\title{
Readiness to Display in the Paradise Fish Macropodus opercularis, L., Belontiidae: The Problem of General and Specific Effects of Social Isolation ${ }^{1}$
}

\author{
ROGER E. DAVIS
}

\author{
The Neuroscience Laboratory and the \\ Mental Health Research Institute, \\ The University of Michigan, \\ Ann Arbor, Michigan 48104
}

\begin{abstract}
The readiness to perform species typical social displays and the readiness to startle in reaction to novel stimuli are increased in socially isolated paradise fish. Males that are kept in large, bisexual populations or have been socially isolated for a few hours show low display and low startle readiness. Reactivity is increased following 1 day of social isolation, and a further increase is obtained by prolonging the isolation up to 4 days. Males that receive continuous visual stimulation from a conspecific male or from a goldfish for 4 days show reduced display and reduced startle readiness. Social isolation appears to have general effects on behavior, increasing reactivity to various kinds of stimuli in addition to social stimuli. It is proposed that isolation-induced increases in display readiness are largely a result of the low level of external stimulation. Social isolation may or may not have specific effects on social display readiness.
\end{abstract}

Laboratory investigations of social behavior in some fishes show that readiness of individuals to perform social displays tends to vary inversely with the recency of social experience. The phrase "display readiness" is used in this report to denote the frequency of occurrence of social displays that are performed during a brief encounter with a live conspecific stimulus or mirror image stimulus. Continuous or repeated presentation of a social stimulus results in adaptation or waning of display in various fishes (Baenninger, 1966, 1970; Baenninger and Mattlemen, 1973; Clayton and Hinde, 1968; Assem and Molen, 1969; Peeke, Wyers, and Herz, 1969; Peeke, 1969; Peeke and Peeke, 1971; Figler, 1972; Brown and Noakes, 1974). The fish in such experiments are individually isolated for a period of days prior to the social stimulation period. Social isolation is one of the most effective procedures for increasing

${ }_{1}$ thank Jessie Shelby and David Marques for their assistance in conducting the experiments. I am further indebted to them and to other colleagues for invaluable discussions related to this work. 
aggressivity in animals, or the apparent readiness of individuals to perform social display and attack one another (e.g., in hermit crabs: Hazlett, 1966; Courchesne and Barlow, 1971; in fishes: Ward, 1967; Pal, 1968; Rasa, 1971; Davis, Harris, and Shelby, 1974; Hinkel and Maier, 1974; Chizar, Henderson, and Scott, 1975; in mammals: Scott, 1966; Krsiak and Janku, 1969; Valzelli, 1969; Lagerspaetz and Lagerspaetz, 1971; Cairns, 1972; Connor, 1974). In some fishes, social isolation results in reduced aggressivity (Heiligenberg, 1964; Gallagher, Herz, and Peeke, 1972).

Few experiments have been carried out to determine exactly what properties of the isolation environment are responsible for the increased reactivity to social stimuli. The assumption which seems implicit in some research (e.g., Lorenz, 1966; Rasa, 1971; Hinkel and Maier, 1974; Davis et al., 1974 ) is that the absence of social, or conspecific stimuli is the key variable.

Social isolation constitutes an unusual situation for a gregarious animal. The individual is deprived of a principal source of its daily, stimulus-response experiences. If the isolation environment is further deficient in alternate response opportunities, such as novel objects or space to explore, the stimulus-response deprivation would be even greater. Isolation deprives the animal of novelty, unpredicability, and generally the chance to manipulate its environment, and the deprivation may have behavioral consequences which complicate interpretation of the effects of other experimental variables (Kavanau, 1964; Hinde, 1970; Cairns, 1972; Garcia, Clarke, and Hawkins, 1972).

In mammals, social isolation increases reactivity to various external stimuli (Welch, 1964; Cairns, 1972; Valzelli, 1973). Individuals show increased irritability, hypertension, and altered pituitary-adrenocortical activity (Welch and Welch, 1969). Similar psychophysiological processes presumably operate in fishes as well. Social isolation might act relatively specifically to increase reactivity to social stimuli, as postulated in various motivational models of social behavior (Hinde, 1970), but it might also act more generally to increase reactivity to various types of stimuli, social and nonsocial stimuli as well. The general effects model suggests that the increased reactivity is not stimulus specific, and that it may be possible to compensate for the absence of social stimuli by substituting an appropriate amount of nonsocial stimulation. For the purposes of this paper, a "social stimulus" is defined as a conspecific stimulus that elicits social display behavior.

In the Davis et al. (1974) investigation on paradise fish, display readiness increased within hours following social isolation and in several days reached high levels. The isolates also showed increased startle reactions when they were handled. Mechanical or photic stimuli that elicit only mild orientation reactions in a fish, which is kept in a tank with other fish, may elicit sudden, profound immobility in a socially isolated individual (e.g., Whelker and Whelker, 1958; Russel, 1967). Typically, the fish sinks to the bottom or 
makes brief erratic swimming movements, as though in escape or search for cover, prior to becoming immobile for a variable period of minutes. Startle readiness in fish can be reduced by continuous presentation of stimuli from selected, nonconspecific fish which do not readily elicit social displays (Barlow, 1968).

The relationship between startle and display readiness in paradise fish suggested that socially isolated fish are generally hyperactive. Any specific effects of social isolation on display readiness might be obscured by the general effects of a low level of stimulation. The evidence that startle readiness can be reduced by exposing a socially isolated fish to nonconspecific fish stimulation suggested a method of determining the relative contributions of general and specific effects of social isolation to display readiness. The rationale was that if increased display readiness in social isolates is a general effect of a low level of external input, then increased social and nonsocial stimulation should reduce it. If display readiness is instead a specific effect of the lack of recent social interaction, then increased social but not nonsocial stimulation, should reduce it. Immature goldfish, Carassius auratus, were used as nonsocial stimuli. In the following experiments, the effect of increasing periods of isolation on startle and display readiness is examined. Subsequently the effects on startle and display readiness of continuous paradise fish and goldfish visual stimulation are compared.

\section{EXPERIMENT 1}

\section{Isolation-Induced Startle Readiness}

This experiment was conducted to determine whether social isolation results in increased startle reactivity in male paradise fish. Individuals surfacing to breathe air react quickly to sudden noise and movement overhead. This adaptive trait suggested a simple method of startling the fish. The experimental startle stimulus comprised a loud sound and high contrast visual stimulus which was presented $4-5 \mathrm{~cm}$ above the fish as it reached the surface to breathe.

\section{Method}

Subjects. The subjects in the following experiments were adult male $M$. opercularis, $3.5-5.3 \mathrm{~cm}$ in body length, which were obtained from Gossington Tropical Fisheries, Del Ray Beach, Florida. They were kept in large tanks with females for at least several weeks prior to the experiment. Water temperatures in the laboratory ranged from 24 to $26^{\circ} \mathrm{C}$, and the rooms were illuminated with Daylight fluorescent light from 0600 to 2000 hours. The fish were fed Tetramin and frozen brine shrimp daily before and during experiments. 
Startle tank. The mirror tank which was used in Davis et al. (1974) was modified for the startle trial (Fig. 1). The mirror was removed and a noise-producing clapper was attached to the top. The clapper consisted of a clear sheet of plastic, $15 \times 25 \times 0.02 \mathrm{~cm}$ thick, which was hinged on the rear wall of the tank. Crossing stripes of black tape on the clapper formed a visual pattern. The free end of the clapper was weighted and it was held aloft by a thread which was controlled by the observer who sat in front of the tank behind a viewing screen (Davis et al., 1974). When the observer released the thread, the clapper fell producing a loud sound as it struck the front wall of the tank. The tank was filled to $16 \mathrm{~cm}$ with charcoal-filtered tapwater. The tank was illuminated by a $20-W$, Cool White fluorescent lamp $30 \mathrm{~cm}$ above the tank.

Procedure. Individual males were kept in separate isolation tanks for $4 \mathrm{hr}, 1$ and 4 days. Following the isolation period, the subject was administered an $8-\mathrm{min}$ startle trial. The subject was transported in a small container and gently poured into the center of the startle tank. The trial was begun when the fish resumed swimming crossing a line of the activity grid. The frequency of subsequent line-crossing activity and of air gulp was measured for $3 \mathrm{~min}$ prior to administration of the startle stimulus and for $5 \mathrm{~min}$ following the stimulus. Air gulp was recorded each time that the fish breathed air at the surface. The behaviors were registered by keyboard with an Esterline Angus event recorder.

The reaction of the subject to the startle stimulus was measured in terms of the resultant suppression of swimming and air breathing. The average frequencies of air gulp and of activity per minute before and after the startle stimulus were used to calculate the percentage of suppression of the behaviors.

\section{Results}

Most subjects responded to the startle stimulus by swiftly descending to the bottom and remaining still for a period of seconds to minutes. The
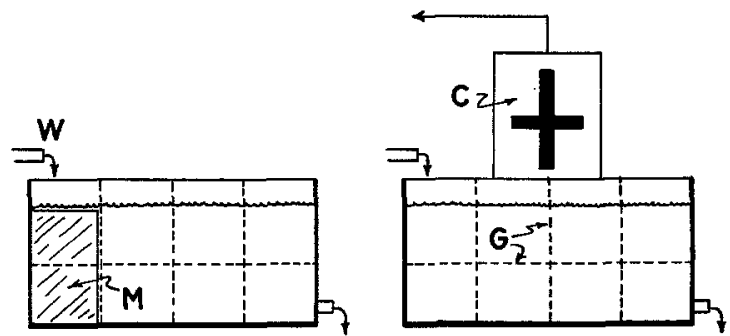

Fig. 1. The experimental tank as prepared for a mirror trial (left) and a startle reaction trial (right). W, dechlorinated tap water, $200-400 \mathrm{ml} / \mathrm{min}, 24-26^{\circ} \mathrm{C} ; \mathrm{G}$, $8 \times 10-\mathrm{cm}$ swimming activity grid which was drawn on the front and rear walls of the tank; $M, 10 \times 16-\mathrm{cm}$ glass mirror on rear wall of the tank; C, clapper which produced the startle stimulus (see text). 
TABLE 1

Isolation-Induced Increase in the Suppression of Activity and Air Gulp Following the Startle Stimulus

\begin{tabular}{cccc}
\hline & & \multicolumn{2}{c}{ Startle trial } \\
\cline { 3 - 3 } $\begin{array}{c}\text { Isolation } \\
\text { period }\end{array}$ & $N$ & $\begin{array}{c}\text { Activity } \\
\text { min-1 }^{-1}\end{array}$ & $\begin{array}{c}\text { Air gulp } \\
\text { min }^{-1}\end{array}$ \\
\hline 4 hr & 9 & 12 & 2 \\
1 day & 9 & 30 & 25 \\
4 days & 9 & 66 & 60 \\
ANOVA & & $F=7.59$ & $F=5.39$ \\
& $P<0.005$ & $P<0.001$ \\
\hline
\end{tabular}

response was reminiscent of the light shock reaction seen in dark adapted fishes (Davis, 1962). Some subjects that were isolated 4 days remained immobile throughout the 5 -min poststartle period. The immobile fish sometimes began opercular movements suggesting increased respiratory stress. Fish that were isolated $4 \mathrm{hr}$ showed the least reaction; some merely halted swimming momentarily and did not descend. One-way analysis of variance (ANOVA) of the mean percentage of suppression of activity and air gulp reveal a significant effect due to duration of isolation (Table 1). The increase in the intensity of the startle reaction, expressed as the suppression of ongoing behaviors, confirmed the impression that several days in the social isolation task increases general reactivity in paradise fish.

\section{EXPERIMENT 2}

\section{Isolation-Induced Display Readiness}

In Davis et al. (1974), experimentally naive fish were administered a single 10-min mirror trial after varying periods in the isolation tank. To investigate the effects of varying the visual environment in the isolation tank on display and startle readiness, it was necessary to measure the response to mirror image stimulation prior to the isolation period, to control for individual variation in initial display readiness. A mirror trial was known to temporarily reduce display readiness. The present experiment was to determine the interval of isolation, following the first mirror trial which was sufficient to restore the readiness to display. 


\section{Procedure}

Thirty-six males were placed in individual isolation tanks for 1 day prior to administration of a 10-min mirror trial (Davis et al., 1974), then immediately isolated for an additional 1,2, 4, or 7 days prior to receiving a second mirror trial. The startle tank in Expt 1 was converted to the mirror tank by placing a $10 \times 16-\mathrm{cm}$-high mirror on the rear wall, in the leftmost column of the activity grid (Fig. 1). Just prior to the trial, the subject was poured into the center of the tank and allowed to explore. The instant that the fish was seen to face its mirror image the $10-\mathrm{min}$ trial was started. The combined frequencies of lateral and frontal display were registered with an event recorder. Lateral display was recorded when the fish fully extended its caudal, anal, and dorsal fins with its body aligned broadside to the mirror. In Frontal display the fish faced the mirror and spread its gill covers (Hall, D. D., 1968; Davis et al., 1974).

\section{Results}

The data for mirror trials 1 and 2 are presented in Table 2. Two-way ANOVA reveals a significant Trials effect $(F(1,32)=32.38, P<0.001)$, an Isolation Period effect $(F(3,32)=4.69, \quad P<0.01)$, and interaction $(F(3,32)=11.77, P<0.01)$. The groups showed equivalent mean frequencies of display in the preliminary mirror trial. In the postisolation trial, display frequency increased with the period of isolation (one-way ANOVA). The 1-day isolates performed displays less frequently in the postisolation trial than in the preliminary trial suggesting that recovery from the reduction in display readiness produced by the trial was incomplete. Significant increases in display frequency, compared to the levels in the preliminary trial, were shown by the 2-, 4-, and 7-day isolates. The readiness to display was substantially increased by 4 days of isolation and 7 days was not significantly more effective.

\section{TABLE 2}

Isolation-Induced Increase in the Frequency of Lateral (LD) plus Frontal (FD) Displays

\begin{tabular}{|c|c|c|c|c|}
\hline \multirow{3}{*}{$\begin{array}{c}\text { Isolation } \\
\text { period } \\
\text { days }\end{array}$} & \multirow[b]{3}{*}{$N$} & \multicolumn{2}{|c|}{ Mirror trial $(10 \mathrm{~min})$} & \multirow{3}{*}{$\begin{array}{c}\text { Paired } \\
t \text { tests }(P)\end{array}$} \\
\hline & & Preliminary & Postisolation & \\
\hline & & Mean LD + FD & Mean LD + FD & \\
\hline 1 & 9 & 40 & 26 & $<0.02$ \\
\hline 2 & 9 & 37 & 54 & $<0.01$ \\
\hline 4 & 9 & 28 & 73 & $<0.005$ \\
\hline 7 & 9 & 31 & 74 & $<0.0009$ \\
\hline \multirow[t]{2}{*}{ ANOVA } & & $F<1$ & $F=5.57$ & \\
\hline & & & $P<0.003$ & \\
\hline
\end{tabular}




\section{EXPERIMENT 3}

\section{Visual Stimulation and Startle Readiness}

Males showed a marked increase in readiness to display during a 4-day period of isolation following a preliminary mirror trial (Table 2). It seemed reasonable to assume from Expt 1 (Table 1) that startle readiness would also be increased during the 4-day interval. The present experiment was to determine whether continuous conspecific and nonconspecific visual stimulation during the 4-day period reduces startle readiness.

Paradise fish which are kept in adjacent, individual tanks respond visually to each other. The fish perform lateral and frontal displays, and swim vigorously at the intervening glass as though to attack. A pair may display to each other intermittently day after day. In contrast, paradise fish seldom display to a nonconspecific, such as a goldfish, Carassius auratus, of similar size. However, an active, colorful goldfish might increase the level of external environmental stimulation and thereby reduce the paradise fish's general reactivity. A conspecific male might increase the level of stimulation to a greater degree than a goldfish. If so, males which have another male as a stimulus during the 4-day period might show lower startle readiness than do males which are exposed to goldfish.

\section{Procedure}

Three groups of nine males were matched for readiness to display in a preliminary mirror trial following 1 day of isolation, then isolated for 4 additional days prior to administration of an 8 -min startle trial. The startle trial procedure is described in Expt 1. During the 4-day period of isolation, the paper covering of one wall of the isolation tank was removed so that the subject could see the interior of the adjacent stimulus tank which was of similar size. The glass walls of the two tanks were $1-2 \mathrm{~cm}$ apart. The stimulus tank contained either no fish, an adult male conspecific, or an immature goldfish. The stimulus fish and the subject were similar in size. In addition to suppression of activity and of air gulp, the period immediately following the startle stimulus during which the fish remained immobile was also measured.

\section{RESULTS}

The members of the conspecific dyads continued intermittently to display to each other during the 4-day period of isolation. In the nonconspecific dyads, the paradise fish oriented to the goldfish and actively swam in its direction but no distinct displays were seen. The goldfish generally were very active, possibly because of the high water temperature, and they 
frequently swam back and forth along the tank walls. The paradise fish which had no fish stimulus were seen hovering in midwater, resting on the bottom, and hiding under or behind the filter; active swimming was uncommon.

The conspecific stimulus group showed less suppression of activity $(P<0.009)$, air gulp $(P<0.002)$, and shorter poststartle immobility $(P<0.05)$ than the no-fish group. The goldfish stimulus group also showed less suppression of air gulp $(P<0.02)$, and shorter poststartle immobility $(P<0.05)$ than the no-fish group but the suppression of swimming activity was not significantly different. Though the conspecific and goldfish stimulus groups showed no significant differences in mean suppression of air gulp or duration of poststartle immobility, the data suggested that reactivity to the startle stimulus was lower in the group which received paradise fish stimulation. Consistent with this impression, swimming activity was suppressed less in the paradise fish stimulus group than in the goldfish stimulus group.

\section{EXPERIMENT 4}

\section{Increased Visual Stimulation and Display Readiness}

The present experiment was conducted to determine whether goldfish visual stimulation reduces display readiness and, if so, whether it is as effective as paradise fish visual stimulation.

\section{Procedure}

The procedure was similar to the Expt 3. The only exception was that instead of the startle trial, following the 4-day isolation period, a postisolation mirror trial was administered as in Expt 2. During the isolation period, the subject viewed an adult conspecific male, an immature goldfish, or no fish. The groups assigned to the different stimulus treatments were matched in mean readiness to display in a preliminary mirror trial as in Expt 3 .

\section{Results}

During the 4-day period of isolation, the behavior of the paradise fish in the no-fish, conspecific, and goldfish stimulus conditions was as described in Expt 3. The mean frequencies of display in the postisolation mirror trial varied with the visual stimulus treatment during the preceding 4 days of isolation (Table 3). The no-fish stimulus group showed a higher frequency of display than the goldfish $(P<0.002)$ and the conspecific $(P<0.0001)$ stimulus groups. Goldfish stimulation resulted in a higher frequency of display than conspecific stimulation $(P<0.02)$. 
TABLE 3

Effects of Prior Conspecific and Visual Stimulation on the Suppression of Activity and Air Gulp, and on the Duration of Immobility Following the Startle Stimulus

\begin{tabular}{|c|c|c|c|c|c|}
\hline \multirow[b]{3}{*}{$\begin{array}{c}\text { Visual } \\
\text { stimulus }\end{array}$} & \multirow[b]{3}{*}{$N$} & \multirow{3}{*}{$\begin{array}{c}\begin{array}{c}\text { Preliminary } \\
\text { mirror trial }\end{array} \\
\text { Mean LD + FD }\end{array}$} & \multicolumn{3}{|c|}{ Startle trial } \\
\hline & & & \multicolumn{2}{|c|}{ Percent suppression } & \multirow{2}{*}{$\begin{array}{c}\text { Poststartie } \\
\text { immobility } \\
\text { (sec) }\end{array}$} \\
\hline & & & $\begin{array}{l}\text { Activity } \\
\min ^{-1}\end{array}$ & $\underset{\min ^{-1}}{\text { Air gulp }}$ & \\
\hline No fish & 9 & 30 & 71 & 66 & 206 \\
\hline Goldfish & 9 & 31 & 60 & 27 & 87 \\
\hline Conspecific & 9 & 28 & 40 & 8 & 43 \\
\hline ANOVA & & $\begin{array}{c}F<1 \\
\text { (matched) }\end{array}$ & $\begin{array}{l}F=5.53 \\
<0.01\end{array}$ & $\begin{array}{l}F=6.49 \\
P<0.006\end{array}$ & $\begin{array}{l}F=3.23 \\
P<0.05\end{array}$ \\
\hline
\end{tabular}

\section{DISCUSSION}

These experiments suggest that the increased intensity of elicited social display which occurs in socially isolated paradise fish is to a great extent attributable to general effects of isolation. The isolate is hyperreactive and the increased intensity of display behavior is one expression of the general reactivity. Whether social isolation has specific effects on display readiness is not clearly determined by the present experiments.

First, it was demonstrated that the social isolation procedure increased reactivity to nonsocial stimuli. This was shown in the startle reaction to the falling of the clapper on top of the tank (Table 1). The startle behavior was morphologically very different from social behavior, and the two types of behavior were elicited by different stimuli. Thus, social isolation seemed to make the fish generally hyperreactive. Second, increased nonsocial stimulation, in the form of visual interaction with an immature goldfish, which reduced startle readiness (general reactivity) also resulted in a substantial reduction of display readiness. Goldfish visual stimuli thus compensated, though not completely, for the lack of paradise fish visual stimuli (Table 4).

If social stimuli are superior to all nonsocial stimuli in reducing display readiness, specific effects of social isolation would be implicated. While the present limited results suggest that male paradise fish are superior to immature goldfish, additional forms of nonsocial stimulation need to be investigated. I would wish to know, for example, the effects on display readness of other fish visual stimuli, of frequent handling by the investigator and various other 
TABLE 4

Effects of Prior Conspecific and Goldfish Visual Stimulation on the Frequency of Lateral (LD) plus Frontal (FD) Displays

\begin{tabular}{lcccl}
\hline & & \multicolumn{2}{c}{ Mirror trial $(10 \mathrm{~min})$} & \\
$\begin{array}{l}\text { Visual } \\
\text { stimulus }\end{array}$ & $N$ & $\frac{\text { Preliminary }}{\text { Mean LD }+ \text { FD }}$ & $\frac{\text { Postisolation }}{\text { Mean LD }+ \text { FD }}$ & $\begin{array}{c}\text { Paired } \\
t \text { test }\end{array}$ \\
\hline No fish & 9 & 28 & 72 & $<0.0005$ \\
Goldfish & 10 & 21 & 23 & $\mathrm{~ns}$ \\
Conspecific & 10 & 24 & 8 & $<0.02$ \\
ANOVA & & $\begin{array}{c}F<1 \\
\text { (matched) }\end{array}$ & $\begin{array}{c}F=17.5 \\
P<0.0001\end{array}$ \\
\hline
\end{tabular}

forms of mechanical stimulation, and of an enriched living space. The superior display eliciting properties of the male paradise fish stimulus compared to the goldfish stimulus, could be responsible for the resultant differences in display readiness. The continuous presentation of male stimuli in the adjacent tank might have resulted in habituation (Peeke and Herz, 1973) and other learning (Lagerspaetz and Lagerspaetz, 1971), which could reduce readiness to display below the level of that produced by continuous exposure to a small goldfish.

If future investigations reveal that nonsocial stimuli can fully compensate for social stimuli in maintaining low display readiness in social isolates, the general reactivity model would be supported. Paradise fish stimuli may be superior to goldfish stimuli not because of specific effects on display behavior, but because they are naturally more stimulating to male paradise fish and maintain a lower level of general reactivity. In line with this view, paradise fish stimuli seemed to be slightly more effective than gold fish in reducing startle readiness (Table 3 ).

In selecting a form of nonsocial stimulation, I chose to use goldfish because their red-orange skin color, stiff-bodied, often frenetic, dither (Barlow, 1968) movements contrast sharply with the predominately black, red, blue integument, the langorous, supple-bodied movements of paradise fish. In addition, immature goldfish do not exhibit patterns of behavior resembling the frontal and lateral display of the paradise fish.

Paradise fish do display to goldfish and to other nonsocial stimuli under certain conditions. In social groups in a seminatural tank, paradise fish which are displaying to each other may display to goldfish which swims too close. A male guarding a nest displays to goldfish and other fishes which approach the nest; it will also sometimes display to a human finger or a thermometer suddenly presented nearby. Paradise fish readily attack, kill, and consume other fishes including goldfish. Not surprisingly, a live goldfish stimulus which is presented behind a clear glass wall can elicit displays in a paradise fish 
which has been kept in the social isolation tank for several days. But the rate of display wanes within a few minutes and does not persist as when the stimulus is another paradise fish. Siamese fighting fish, Betta splendens, a relative of the paradise fish in the subfamily Macropodinae, displays to nonconspecific fish and paper images of fish under similar extraordinary environmental conditions (Johnson and Peeke, 1972; Johnson, and Johnson, 1973). It seems unlikely that the display-eliciting properties of the goldfish could be responsible for the reduction of display readiness which occurred during the 4-day period of isolation.

The isolation-induced increases in display readiness could, in my view, be an expression of the general psychophysiological response to a low level of environmental stimulation, which has been postulated by Welch (1964) to be a major factor in determining how the individual animal behaves in a situation. It is commonplace in experiments on agonistic behavior to socially isolate the subject without a compensatory increase in nonsocial stimulation. Increased intensity of agonistic behavior resulting from unnaturally low levels of external input could conceivably override or obscure the operation of physiological variables which otherwise control such behavior.

Machemer (1970) reported that methyltestosterone administered to intact male paradise fish results in increased aggressive behavior. Our laboratory was unable to obtain such effects. The males in our (unreported) experiments were socially isolated and showed high levels of display and attack readiness prior to the hormone administration. The possibility that aggressivity due to general effects of isolation, exacerbated by the unnaturally low level of external stimulation, masked the effects of exogenous androgen led to the present investigation. Experiments on the effects of variation in androgen hormone levels on social behavior in fish which are kept in environmentally enriched, seminatural aquaria are in progress.

In a natural, or seminatural habitat where the average level of nonsocial, external environmental stimulation is presumably high, it may be possible to detect fluctuations in readiness to respond to social stimuli due to specific effects of social isolation. In male sticklebacks, Gasterosteus aculeatus, social reactivity is reported to be reduced by prior conspecific, but not goldfish, visual stimulation (Assem and Molen, 1969; Jenni, Iersel, and Assem, 1969). Heiligenberg (1964) showed that attack readiness in a cichlid, Pelmatochromis subocellatus kribensis, is reduced (not increased) following weeks of social isolation, and that it can be increased by administering brief daily encounters with another individual. Long-term isolates will show biting attack if they are transferred to an unfamiliar living space the day before the postisolation, social encounter, and also if the intruder attacks them. Another cichlid, Cichlasoma nigrofasciatum, is reported to show reduced readiness to approach a conspecific in a nearby "combat" area, in comparison to individuals which are continuously exposed to other fishes (Gallagher, Herz, and Peeke, 1972). 
Comparison of effects of social isolation on social behavior in different species may be complicated by differences in experimental procedures (Cairns, 1972).

Social isolation in the hermit crab, Pagurus samuelis, results in increased frequency of some social behaviors, mainly those which are associated with intense fighting, while those which appear to be less aggressive do not increase (Courchesne and Barlow, 1971). Experiments in another hermit crab, Calcinus tibicen, showed that social isolation produces increased aggressivity and locomotion. Aggressivity was not reduced by visual contact with other physically isolated crabs; the visual stimulation seemed, if anything, to increase social reactivity. In still another crustacean, the lobster, Homarus americanus, individuals which are housed in groups or physically isolated but in continuous visual contact show less social reactivity than totally isolated lobsters (Hoffman, Dunham, and Kelly, 1975).

Isolation-induced aggressivity has been investigated most extensively in laboratory rodents. In socially isolated mice, aggressivity develops over a period of weeks or months (Krsiak and Janku, 1969; Lagerspaetz and Lagerspaetz, 1971), instead of hours to days as paradise fish (Pal, 1968; Davis et al., 1964). The absence specifically of male stimuli may be a cause of isolation-induced fighting readiness in isolated male mice. Males housed with females fight as intensely as males which have been socially isolated, whereas males housed with males or with males and females show reduced aggressivity (Crawley, Schleidt, and Contrera, 1975). Harmantz, Boelkins, and Kessler (1975) propose that males housed in groups may produce a pheromone which suppresses fighting, and that the increase in aggressivity which develops in socially isolated males is a result of disinhibition from the effects of the pheromone.

Social reactivity in paradise fish may or may not be influenced by conspecific pheromones. In the present experiment, intermale chemical stimulation was prohibited, as the subject and the stimulus were kept in separate tanks. Solitary paradise fish are attracted to water which has contained a conspecific male or female (Davis and Pilotte, 1975). Individuals occasionally perform lateral display toward the source of a flow of water when stimulus water is added. If chemical stimuli are discriminated as social stimuli, prolonged exposure to water containing the stimuli might result in reduced social reactivity. In male Siamese fighting fish, the presence of male chemical stimuli in an unfamiliar environment results in reduced display toward a stimulus fish in a separate container (Ingersoll, Bronstein, and Bonventre, 1975). Heiligenberg (1964) isolated the cichlids in separate compartments with a movable partition. It is not clear whether movement of chemical stimuli between compartments was possible and, if so, whether the stimulation contributed to the reduction of aggressivity after weeks of isolation which he observed. Chemical stimuli have potent, specific effects on social and reproductive behavior in fishes (Bardach and Villars, 1974). More research is needed to determine whether pheromones play a role in determining social reactivity. 


\section{REFERENCES}

Assem, J. van der, and Molen, J. N. van der (1969). Waning of the aggressive response in the three-spined stickleback upon constant exposure to a conspecific. I. A preliminary analysis of the phenomenon. Behaviour 34, 286-324.

Baenninger, R. (1966). Waning of aggressive motivation in Betta splendens. Psychon. Sci. 4, 241-242.

Baenninger, R. (1970). Visual reinforcement, habituation, and prior social experience of Siamese fighting fish. J. Comp. Physiol. Psychol. 71, 1-5.

Baenninger, R., and Mattlemen, R. A. (1973). Visual reinforcement: Operant acquisition in the presence of a free mirror. Anim. Learning Behav. 1, 302-306.

Bardach, J. E., and Villars, T. (1974). The Chemical senses of fishes. In P. T. Grant and A. N. Mackie (Eds.), "Chemoreception in Marine Organisms," pp. 49-104. New York: Academic Press.

Barlow, G. W. (1968). Dither-A way to reduce undesirable fright behavior in ethological studies. Z. Tierpsychol. 25, 315-318.

Brown, D. M. B., and Noakes, D. L. G. (1974). Habituation and recovery of aggressive display in paradise fish (Macropodus opercularis (L.) Behav. Biol. 10, 519-525.

Cairns, R. B. (1972). Fighting and punishment from a developmental perspective. Nebraska Symp. Motiva. 20, 59-124.

Chizar, D., Ashe, V., Seixas, S. and Henderson, D. (1975). Social-aggressive behavior after various intervais of social isolation in bluegill sunfish (Lepomis macrochirus Rafinesque) in different states of reproductive readiness. Submitted for publication.

Clayton, F. L., and Hinde, R. A. (1968). The habituation and recovery of aggressive display in Betta splendens. Behaviour 30, 96-105.

Connor, J. L. (1974). Waning and recovery of conspecific aggression in the house mouse (Mus musculus L.). J. Comp. Physiol. Psychol. 87, 215-227.

Courchesne, E., and Barlow, G. W. (1971). Effect of social isolation on components of aggressive and other behavior in the hermit crab, Pagurus samuelis. Z. Vergl. Physiol. 75, 32-48.

Crawley, J. N., Schleidt, W. M., and Contrera, J. F. (1975). Does social environment decrease propensity to fight in male mice? Behav. Biol. 15, 73-83.

Davis, R. E. (1962). Daily thythm in reaction of fish to light. Science 137, 430-432.

Davis, R. E., Harris, C., and Shelby, J. (1974). Sex differences in aggressivity and the effects of social isolation in the anabantoid fish, Macropodus opercularis. Behav. Biol. 11, 497-509.

Davis, R. E., and Pilotte, N. J. (1975). Attraction to conspecific and nonspecific chemical stimuli in male and female Macropodus opercularis (Teleostei, Anabantoidei). Behav. Biol. 13, 191-196.

Figler, M. H. (1972). The relation between eliciting stimulus strength and habituation of the threat display in male Siamese fighting fish, Betta splendens. Behaviour 42, 63-96.

Gallagher, J. E., Herz, M. J., and Peeke, H. V. S. (1972). Habituation of aggression: The effects of visual social stimuli on behavior between adjacently territorial convict cichlids. Behav. Biol. 7, 359-368.

Garcia, J., Clarke, J. C., and Hankins, W. G. (1973). Natural responses to scheduled rewards. In P. P. G. Bateson and P. H. Klopfer (Es.), "Perspectives in Ethology," pp. 1-38. New York: Plenum Press.

Hall, D. D. (1968). A quantitative analysis of courtship and reproductive behavior in the paradise fish, Macropodus opercularis (Linnaeus). Z. Tierpsychol. 25, 834-842. 
Harmantz, R., Boelkins, C., and Kessler, S. (1975). Postisolation aggression and olfactory cues. Behav. Biol. 13, 219-224.

Hazlett, B. A. (1966). Factors affecting the aggressive behavior of the hermit crab Calcinus tibicen. Z. Tierpsychol. 6, 655-671.

Hinde, R. A. (1970). "Animal Behaviour: A Synthesis of ethology and Comparative Psychology," 2nd ed. New York: McGraw-Hill.

Hinkel, T. J. and Maier, R. (1974). Isolation and aggression in Siamese fighting fish (Betta splendens). Psychol. Rep. 34, 1323-1326.

Hoffman, R. S., Dunham, P. J., and Kelly, P. V. (1975). Effects of water temperature and housing conditions upon the aggressive behavior of the lobster Homarus americanus. J. Fish. Res. Bd. Can. 32, 713-717.

Ingersoll, D. W., Bronstein, P. M., and Bonventre, J. (1975). The chemical modulation of agonistic display in Betta splendens. J. Comp. Physiol. Psychol., in press.

Jenni, D. A., Iersel, J. J. van, and Assem, J. van der (1969). Effects of pre-experimental conditions on nest site selection and aggression in Gasterosteus aculeatus L. Behaviour 35, 61-76.

Johnson, H. G., and Peeke, H. V. S. (1972). Patterns of intra- and interspecific aggression in labyrinth fish (Belontiidae). Behav. Biol. 7, 335-347.

Johnson, R. N., and Johnson, L. D. (1972). Intra- and interspecific social and aggressive behaviour in the Siamese fighting fish, Betta splendens. Anim. Behav. 21, 665-672.

Kavanau, J. L. (1964). Behavior: Confinement, adaptation, and compulsory regimes in laboratory studies. Science 143, 490.

Krsiak, M., and Janku, I. (1969). The development of aggressive behavior in mice by isolation. In S. Garratini and E. G. Sigg (Eds.), "Aggressive Behaviour," pp. 101-105, New York: Wiley.

Lagerspaetz, K., and Lagerspaetz, K. Y. H. (1971). Changes in the aggressiveness of mice resulting from selective breeding, learning and social isolation. Scand. J. Psychol. 12, 241-248.

Lorenz, K. (1966). "On Aggression." New York: Harcourt Brace and World.

Pal, B. C. (1968). Effect of length of isolation and degree of domestication on aggressive behavior in Indian paradise fish, Macropodus cupanus. Amer. Zool. 8, 750 (Abstr.)

Peeke, H. V. S. (1969). Habituation of conspecific aggression in the three-spined stickleback (Gasterosteus aculeatus L.). Behaviour 35, 137-156.

Peeke, H. V. S., and Herz, M. J. (1973). "Habituation. I. Behavioral Studies." New York: Academic Press.

Peeke, H. V. S., and Peeke, S. (1970). Habituation of conspecific aggressive responses in the Siamese fighting fish (Betta splendens) 36, 232-245.

Peeke, H. V. S., Wyers, E. J., and Herz, M. J. (1969). Waning of aggressive response to male models in the 3-spined sticklebach (Gasterosteus aculeatus L.). Anim. Behav. 17, 224-228.

Rasa, O. A. E. (1971). Appetence for aggression in juvenile damsel fish. Z. Tierpsychol. Suppl. 7, 1-67.

Russel, E. M. (1967). Changes in the behaviour of Lebistes reticulatus upon a repeated shadow stimulus. Anim. Behav. 15, 574-585.

Scott, J. P. (1966). Agonistic behavior of mice and rats: A review. Amer. Zool. 6, 683-701.

Valzelli, L. (1969). Aggressive behaviour induced by isolation. In S. Garattini and E. G. Sigg (Eds.), "Aggressive Behaviour," pp. 70-76, New York: Wiley.

Valzelli, L. (1973). The "isolation syndrome" in mice. Psychopharmacologia (Berlin) 31, 305-320.

Ward, R. W. (1967). Ethology of the paradise fish, Macropodus opercularis. I. Differences between domestic and wild fish. Copeia 4, 809-813. 
Welch, B. L. (1964). Psychophysiological response to a mean level of environmental stimulation: a theory of environmental integration. In "Symposium of the Medical Aspects of Stress in the Military Climate." Wasington D.C.: Walter Reed Army Medical Center.

Welch, B. L. and Welch, A. S. (1969). Aggression and the biogenic neurohumors. In S. Garrattini and E. B. Sigg (Eds.), "Aggressive Behaviour," pp., 188-202. New York: Wiley.

Welker, W. I., and Welker, J. (1958). Reaction of fish (Eucimostomus gula) to environmental changes. Ecology 39, 283-288. 